\title{
A MAGNETIC HUMUS CORE-SHELL COMPOSITE SYNTHESIZED BY ABIOTIC HUMIFICATION METHOD FOR CR(VI) REMOVAL
} Xinwei Dong and Dongbei Yue *

School of Environment, Tsinghua University, Beijing 100084, China

Article Info:
Received:
13 August 2020
Revised:
6 January 2021
Accepted:
8 January 2021
Available online:
31 March 2021
Keywords:
Abiotic humification
Magnetic humus
Cr(VI) adsorption

\section{INTRODUCTION}

Humus is a type of naturally transformed organic macromolecular material obtained from fresh organic residues, mainly animal and plant remnants. This compound is suitable for use as a sorbent material due to the presence of a variety of active functional groups, including carboxyl, phenolic hydroxy, carbonyl, methoxy, and amino groups, which feature a high capacity of adsorption for heavy metals in water resources (Liu et al., 2016; Singhal et al., 2017; Yang et al., 2012). However, the high solubility of humus limits its practical applications.

To compensate for the disadvantage of high solubility of humus, immobilization of this material on different solid materials such as biochar and $\mathrm{TiO}_{2}$ particles is recommended. Magnetic nanoparticles $\left(\mathrm{Fe}_{3} \mathrm{O}_{4}\right)$ resemble remarkable merits in separation of materials due to magnetic properties and efficient immobilization because of high surface area and rich hydroxyl groups on their surface (Peng et al., 2012; Singhal et al., 2019, 2020a, 2020b). As reported, the high affinity of humus to $\mathrm{Fe}_{3} \mathrm{O}_{4}$ nanoparticles strongly inproves stability of magnetic humus and promotes the nanodispension of $\mathrm{Fe}_{3} \mathrm{O}_{4}$ nanoparticles (Koesnarpadi et al., 2017; Rashid et al., 2018; Tang et al., 2016). But the weight of natural humus loaded on $\mathrm{Fe}_{3} \mathrm{O}_{4}$ is limited because of the district steric hindrances in the humus loading process. These limitations have a negative effect on the perfor- mance of magnetic humus in water treatment.

The artificial humus obtained from a polyphenol-maillard polymerization reaction has the advantages of controllable synthesis process and is considered as an acceptable alternative (Zhang et al., 2017, 2019). The humification process can easily attain synthesized humus with different molecular sizes via regulation of temperature, time and air supply. This kind of mouldability in molecular size is an effective approach to reduce steric hindrances in the humus loading process. The structure of humus highly relies on the variety of humus precursors and humification conditions (Zhang et al., 2017). According to Yang's study, the amount of acidic functions on the synthesized humus is much higher than that of the natural one, allowing the former to possess a better complexation ability towards heavy-metal contaminated soil remediation (Yang \& Hodson, 2018). This means that the structure of synthesized humus could be designed as required. Therefore, these advantages enabled humus to be applied in the environmental remediation.

In this work, a new method is disclosed to prepare magnetic humus (Figure 1) with a high efficacy in the removal of heavy metals. $\mathrm{Fe}_{3} \mathrm{O}_{4}$ nanoparticles were used to enhance humification, integrating small molecular precursors including catechol, glycine, and glucose into humus. To improve loading of the synthesized humus on $\mathrm{Fe}_{3} \mathrm{O}_{4}$ nanopar- 
ticles, $\mathrm{pH}$ was regulated in the synthesis process. The surface morphology of magnetic humus was confirmed by TEM. Eventually, the performance of the generated humus was evaluated in the removal of $\mathrm{Cr}(\mathrm{VI})$ from a solution contaminated by $7.30 \mathrm{mg} / \mathrm{L}$ hexavalent chromium.

\section{MATERIALS AND METHOD}

\subsection{Chemicals and apparatus}

Catechol (> 99\% purity) was purchased from Tokyo Chemical Industry. Glycine ( $>99 \%$ purity) and glucose (> $99 \%$ purity) were obtained from Nacalai Tesque. Potassium dichromate was purchased from Beijing Chemical Works. $\mathrm{Fe}_{3} \mathrm{O}_{4}$ nanoparticles were obtained under oxygen-free conditions. Briefly, $\mathrm{FeCl}_{3} \cdot 6 \mathrm{H}_{2} \mathrm{O}(24.35 \mathrm{~g})$ was dissolved in 250 $\mathrm{mL}$ ultrapure water $\left(70^{\circ} \mathrm{C}\right)$ and added to a $250 \mathrm{~mL}$ solution of FeSO $\cdot 7 \mathrm{H}_{2} \mathrm{O}$. Then, $\mathrm{NH}_{3} \cdot \mathrm{H}_{2} \mathrm{O}$ solution $(90 \mathrm{~mL})$ was added to the above mixture and incubated at $300 \mathrm{rpm}$ for $90 \mathrm{~min}$. After that, the mixture was set in an external magnetic field, the precipitate was separated and washed for five times using deionized water. Finally, the synthesized magnetic humus was resuspended in ultrapure water for further usage.

The transmission electron microscope (TEM) images were obtained using a Tecnai G2 F20 S-Twin electron microscope (FEI, USA). The TOC-V CSN type analyzer (Shimadzu, Japan) was used to analyze the DOC of humus. A PE-Optima 8000 Inductively Coupled Plasma Emission Spectrometer was used to analyze the total amount of $\mathrm{Cr}$, while the amount of $\mathrm{Cr}(\mathrm{VI})$ was determined by UV-1601 (Shimadzu, Japan).

\subsection{Experiments}

Magnetic humus was synthesized in a conical flask $(1000 \mathrm{~mL})$ at $35^{\circ} \mathrm{C}$ with shaking at $200 \mathrm{rpm}$. $\mathrm{Fe}_{3} \mathrm{O}_{4}$ nanoparticles $(2000 \mathrm{mg} / \mathrm{L})$ were added into the solution involving the precursors of catechol (3500 mg C/L), glycine (1750 $\mathrm{mg} \mathrm{C} / \mathrm{L}$ ) and glucose (1750 $\mathrm{mg} \mathrm{C/L})$. To investigate the effect of $\mathrm{pH}$ on the weight of loaded humus on the surface of $\mathrm{Fe}_{3} \mathrm{O}_{4}$ nanoparticles, the initial $\mathrm{pH}$ of $\mathrm{Na}_{2} \mathrm{HPO}_{4} / \mathrm{NaH}_{2} \mathrm{PO}_{4}$ solution $(0.2 \mathrm{M}, 500 \mathrm{~mL})$ was set to $4,6,8$, and 10 .
$1.0 \mathrm{~mL}$ samples were withdrawn from the flask at 0,4 , $9,20,32,45,80,120,160,260,360$ and $500 \mathrm{~h}$ intervals and set in an external magnetic field for solid-liquid separation. A $0.1 \mathrm{~mL}$ aliquot withdrawn from the above supernatant was diluted to $10 \mathrm{~mL}$ and subjected to UV-Vis absorption spectroscopy at $400 \mathrm{~nm}$. Another $0.5 \mathrm{~mL}$ sample was diluted to $20 \mathrm{~mL}$ and used to dissolve the organic carbon content before analysis, while, the magnetic humus was used to humus loading analysis. Briefly, the magnetic humus was separated from a $10 \mathrm{~mL}$ solution with an external magnet and extracted for three times by $3 \times 10 \mathrm{~mL} \mathrm{NaOH}$ solution $(0.1 \mathrm{M})$. After that, the obtained $\mathrm{NaOH}$ solutions were analyzed by a TOC analyzer with the extraction efficiency of $84.86 \%$. The magnetic humus separated from the incubated samples for $500 \mathrm{~h}$ was applied for the TEM surface morphology study.

\section{RESULTS AND DISCUSSION}

\subsection{Reinforcement effect in the darkening experi- ment}

The formation of organic chromophoric groups due to the darkening effect of humification and generation of the browning substances, as a key process of humification, can be justified through studying absorbance at $400 \mathrm{~nm}$. $\mathrm{Fe}_{3} \mathrm{O}_{4}$ nanoparticles were used to enhance the humification in four systems with the $\mathrm{pH}$ of $4,6,8$ and 10 . The absorbance of supernatant solutions at $400 \mathrm{~nm}$ was varied with incubation time, as shown in Figure $2 \mathrm{~A}$. When $\mathrm{pH}$ was set to 4 , the slow increase of supernatant absorbance indicated slow humification reaction throughout the entire experimental process. While, absorbance of the extracted humus from the magnetic counterpart was sharply increased in the first $45 \mathrm{~h}$ and, then, remained constant (Figure 2B). This observation could be explained by the fact that humus has been formed fast in the first $45 \mathrm{~h}$, followed by adsorption on $\mathrm{Fe}_{3} \mathrm{O}_{4}$ nanoparticles to form a core-shell composite through electrostatic forces. However, the shell-like humus directly covered the active sites of $\mathrm{Fe}_{3} \mathrm{O}_{4}$ nanoparticles and weakened its ability to enhance humification. This behavior can also be found in the humification process at $\mathrm{pH} 6$, but

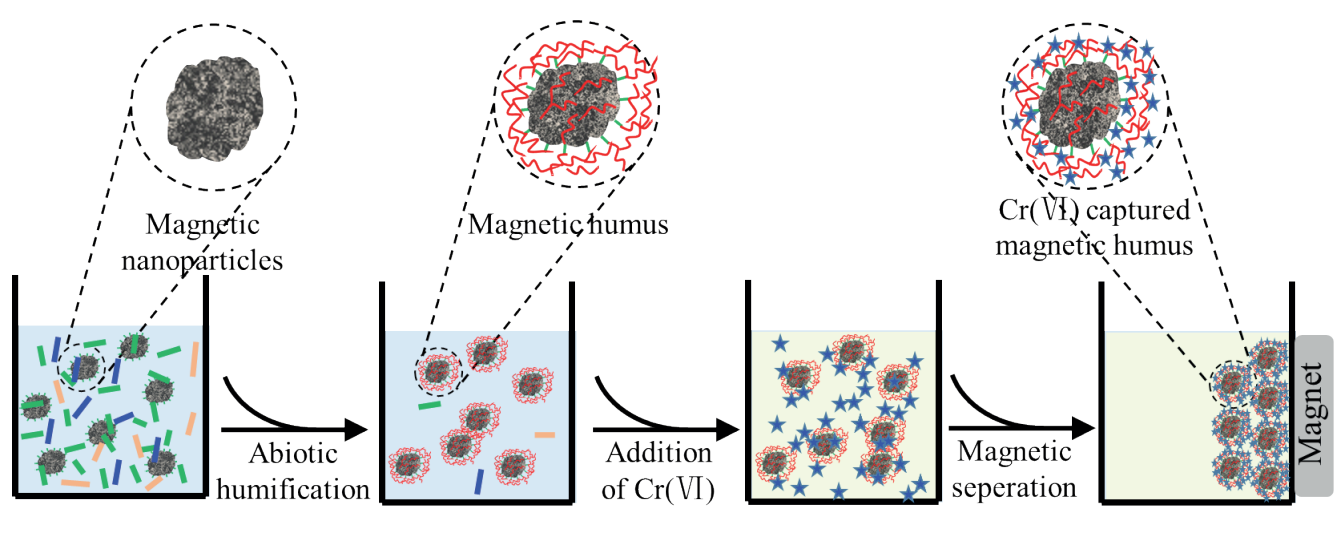

- Catechol - Glycine - Glucose Humus $\star \mathrm{Cr}(\mathrm{VI})$

FIGURE 1: Representations of the procedures for magnetic humus preparation and $\mathrm{Cr}(\mathrm{VI})$ removal. 
the supernatant samples were gradually darkened as the extension of incubation time and, finally, the absorbance reached to 0.60 after $500 \mathrm{~h}$ incubation. This finding suggested that the colored humus has been continuously generated. By contrast, the absorbance of supernatant solution at pHs of 8 and 10 was sharply increased over time within the first $45 \mathrm{~h}$, and then set at a nearly constant value of 1.15 , suggesting that the humus has been significantly generated and reached to a maximum weight after 45 h. On the other hand, absorbance of the extracted humus showed a similar trend with that of supernatant samples. The slight increase of absorbance after $45 \mathrm{~h}$ could be due to the connection of free small amount of humus to magnetic humus under the action of metal oxides. Therefore, the alkaline condition is suitable to enhance humification on $\mathrm{Fe}_{3} \mathrm{O}_{4}$ nanoparticles in the presence of catechol, glycine, and glucose as precursors.

\subsection{Generation of magnetic humus}

The TEM image of $\mathrm{Fe}_{3} \mathrm{O}_{4}$ nanoparticles confirmed that $\mathrm{Fe}_{3} \mathrm{O}_{4}$ nanoparticles have a regular spherical shape with the uniform size of about $11.59 \pm 0.23 \mathrm{~nm}(\mathrm{n}=17)$, as shown in Figure 3A. The inset of this figure shows a lattice with the width of $0.26 \mathrm{~nm}$ for $\mathrm{Fe}_{3} \mathrm{O}_{4}$ nanoparticles. The magnetite nanoparticles were surrounded by a layer of an organic material after coating with humus (Figure $3 \mathrm{~B}$ ). This organic material can be extracted by $0.1 \mathrm{M} \mathrm{NaOH}$ for total organic carbon analysis.

The weight of humus loaded on $\mathrm{Fe}_{3} \mathrm{O}_{4}$ nanoparticles was analyzed, as depicted in Figure 4. The total organic carbon of humus on the surface of $\mathrm{Fe}_{3} \mathrm{O}_{4}$ nanoparticles was detectable, confirming the successful synthesis of magnetic humus. It is clearly demonstrated that humus can gradually grow on the surface of $\mathrm{Fe}_{3} \mathrm{O}_{4}$ nanoparticles, as the carbon content was varied with the incubation time throughout the entire experiments. Due to the faster generation of humus in an alkaline condition, the humus loading on $\mathrm{Fe}_{3} \mathrm{O}_{4}$ nanoparticles was higher under this condition compared to that in the acidic environment. The $\mathrm{Fe}_{3} \mathrm{O}_{4}$ nanoparticles separated at $\mathrm{pH} 8$ and under the incubation time of $500 \mathrm{~h}$ revealed the largest amount of humus with the total carbon content of $243.13 \mathrm{mg}$ per gram of
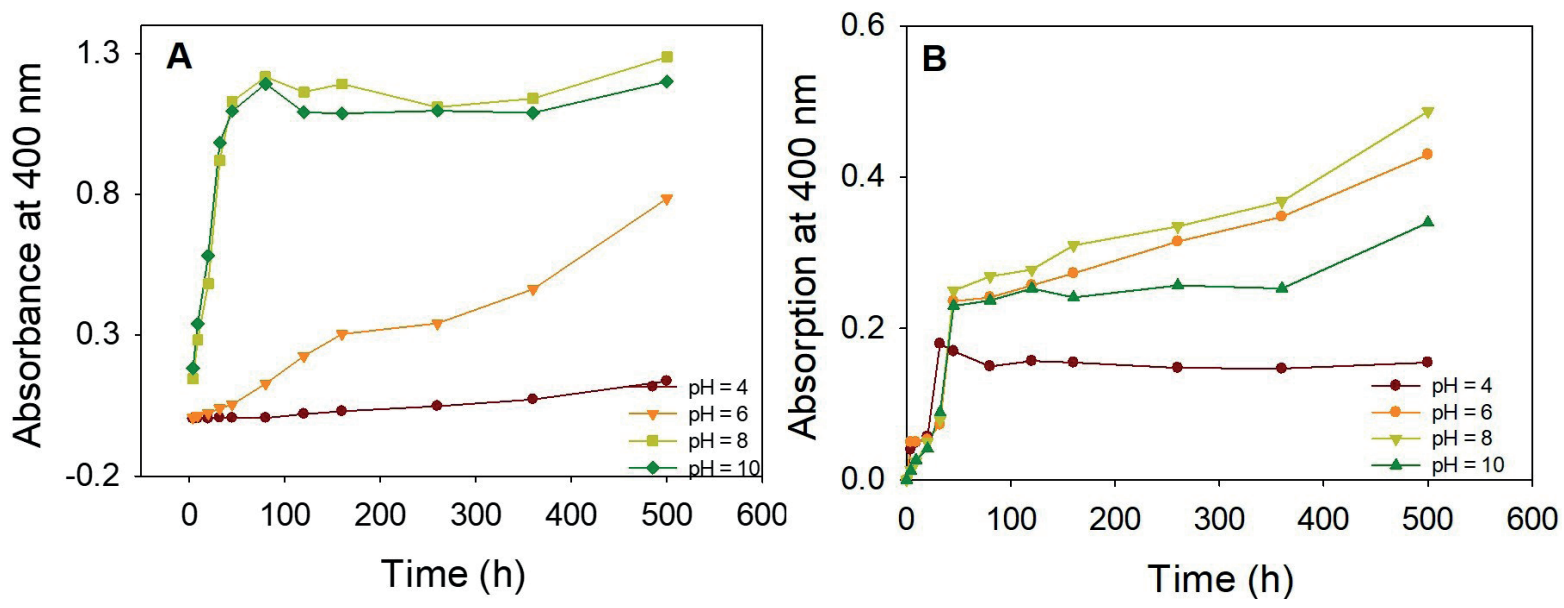

FIGURE 2: Absorbance at $400 \mathrm{~nm}$ of (A) the supernatant solutions after 100 times dilution (B) the extracted humus from the magnetic humus after 50 times dilution.
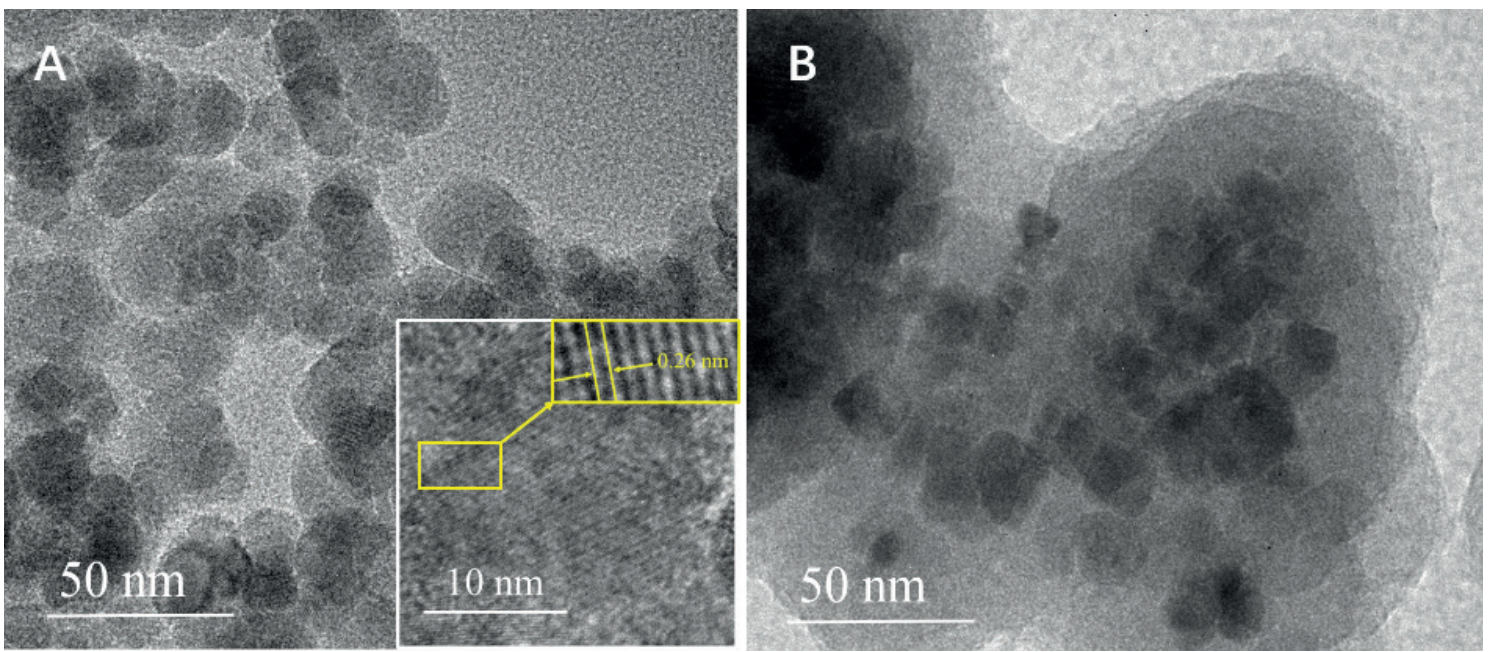

FIGURE 3: TEM images of (A) Fe304 and (B) magnetic humus. 
nanoparticles, which was about $0.5 \mathrm{mg}$ humus $/ \mathrm{mg} \mathrm{Fe}_{3} \mathrm{O}_{4}$ based on the humus carbon percentage of $48.54 \%$ (Zhang et al., 2015). Therefore, the magnetic humus should be contained $33.37 \%$ humus, which is much higher than $11 \%$ attained in the previous report (Liu, et al., 2008). This observation can be explained by consideration of the further exposure of $\mathrm{Fe}_{3} \mathrm{O}_{4}$ active sites involved in the humification process under alkaline condition. These active sites contribute to the formation of humus with a higher aromaticity, so more active sites mean a higher generation rate of humus (Zou et al., 2020). Instead of the spherical structure at a low $\mathrm{pH}$, humus was existed in a rather linear or stretched structure at high $\mathrm{pH}$ values, as alkaline conditions contribute to the formation of further amounts of humus. This is because the dissolution process of humus avoids occupying further spaces and provides more free spaces for the humus formation near the metal oxide surface. However, too high $\mathrm{pH}$ is not conducive to the binding of humus with nanoparticles, therefore, the $\mathrm{pH}$ of 8 was adjusted for the generation of magnetic humus.

\subsection{Availability of the synthesized magnetic humus}

To investigate the ease of separation, performance of the magnetic humus was evaluated in an external magnetic field. As shown in Figure 5, the magnetic humus was scattered in the solution, even after $1 \mathrm{~h}$ incubation, in the absence of an external magnetic field. This finding proved good dispersion of the magnetic humus. However, the suspended magnetic humus can be quickly attracted towards a permanent magnet in $2 \mathrm{~min}$, confirming the utility of magnetic humus separation in the presence of an external magnetic field.

The stability of magnetic humus was evaluated in distilled water. After shaking at $200 \mathrm{rpm}$ for $12 \mathrm{~h}$, the supernatant was collected and analyzed with a TOC analyzer to detect the leached humus. The concentration of free carbon was less than $15 \mathrm{mg} / \mathrm{L}$ (as TOC), indicating only $6.17 \%$ of humus has been leached. The main reason to explain this phenomenon is that the surface of $\mathrm{Fe}_{3} \mathrm{O}_{4}$ nanoparticles bear a negative charge $(\mathrm{PZC}=7.9)$ at $\mathrm{pH} 8$, which

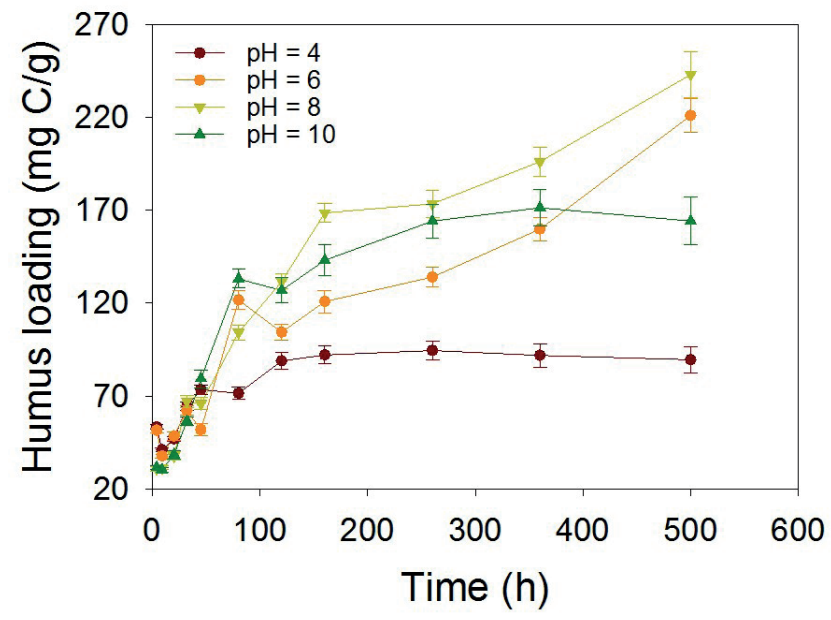

FIGURE 4: Effect of $\mathrm{pH}$ on humus loading in different incubation times. avoids the electrostatic attraction of $\mathrm{Fe}_{3} \mathrm{O}_{4}$ nanoparticles to the negatively charged humus and achieves growing of humus on the surface of $\mathrm{Fe}_{3} \mathrm{O}_{4}$ by covalent binding. Thus, the humus loading would be further enhanced apart from $\mathrm{pH}$ variation, upon addition of a non-magnetic metal oxide with enhanced humification function. Therefore, the outer humus molecules can be connected to form a bigger humus molecule through covalent bonding, which result in a big network, enclose the inner humus and avoid the inner humus molecular diffusion. In this way, the humus loading, as well as its stability would be enhanced.

In order to evaluate application of the synthesized humus in water treatment, the magnetic humus was added to a water sample solution containing $7.30 \mathrm{mg} / \mathrm{L}$ of $\mathrm{Cr}(\mathrm{VI})$. After $6 \mathrm{~h}$, the synthesized magnetic humus $(4 \mathrm{mg} / \mathrm{mL})$ showed a high adsorption efficiency of $99.17 \%$ to $\mathrm{Cr}(\mathrm{VI})$ with the final concentration of $60 \mu \mathrm{g} / \mathrm{L}$, which was lower than the maximum contaminant limits for the total chromium in drinking water $(100 \mu \mathrm{g} / \mathrm{L})$, as announced by the United States Environmental Protection Agency.

\section{CONCLUSIONS}

A new abiotic humification method is presented to synthesize magnetic humus with a high performance for $\mathrm{Cr}(\mathrm{VI})$ adsorption. The change of TEM image after humus loading indicated the successful synthesis of magnetic humus. pH greatly affects formation of humus and weight of the humus loaded on $\mathrm{Fe}_{3} \mathrm{O}_{4}$ nanoparticles. When $\mathrm{pH}$ is set to 8 , the largest loading weight would be obtained, which accounts for $33.37 \%$ of the synthesized magnetic humus. The prepared magnetic humus exhibits good separation ability in aqueous solution and a high adsorption efficiency of $99.17 \%$ can be attained for $\mathrm{Cr}(\mathrm{VI})$. Therefore, the synthesized magnetic humus can be recommended as a potential candidate to remove $\mathrm{Cr}(\mathrm{VI})$ from water resources.

\section{ACKNOWLEDGEMENTS}

The research was supported by the National Key R\&D Program of China (No. 2018YFC1901405).

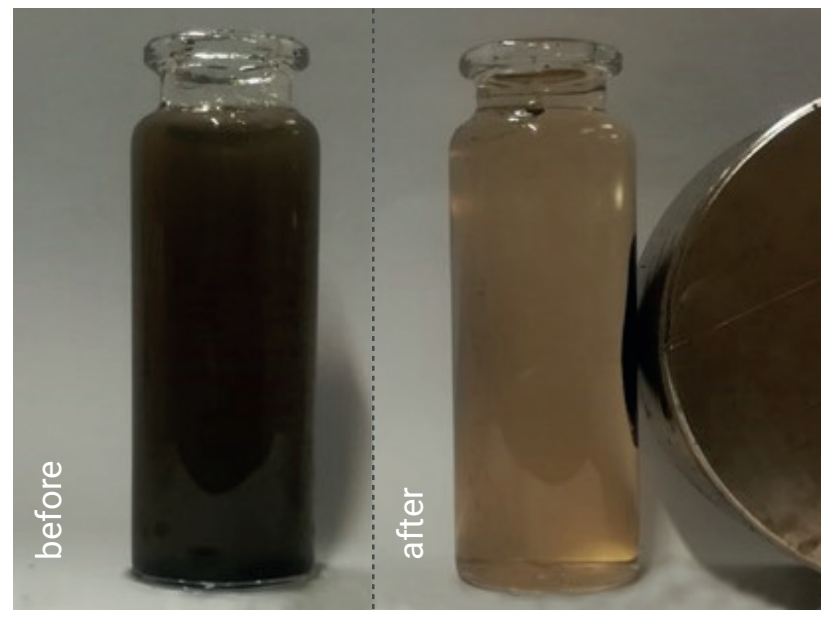

FIGURE 5: Digital images of magnetic humus without or with an external magnetic field added. 


\section{REFERENCES}

Koesnarpadi, S., Santosa, S. J., Siswanta, D., \& Rusdiarso, B. (2017). Humic Acid Coated Fe304 Nanoparticle for Phenol Sorption. Indonesian Journal of Chemistry, 17(2), 274-283. doi:10.22146/ijc.22545

Liu, J. F., Zhao, Z. S., \& Jiang, G. B. (2008). Coating Fe304 magnetic nanoparticles with humic acid for high efficient removal of heavy metals in water. Environmental Science \& Technology, 42(18), 6949-6954. doi:10.1021/es800924c

Liu, Y. G., Li, T. T., Zeng, G. M., Zheng, B. H., Xu, W. H., \& Liu, S. B. (2016). Removal of $\mathrm{Pb}(\mathrm{I})$ from aqueous solution by magnetic humic acid/ chitosan composites. Journal of Central South University, 23(11), 2809-2817. doi:10.1007/s11771-016-3344-1

Peng, L., Qin, P. F., Lei, M., Zeng, Q. R., Song, H. J., Yang, J., Shao J., Liao B.H., Gu, J. D. (2012). Modifying Fe304 nanoparticles with humic acid for removal of Rhodamine $B$ in water. Journal of Hazardous Materials, 209, 193-198. doi:10.1016/j.jhazmat.2012.01.011

Rashid, M., Sterbinsky, G. E., Pinilla, M. A. G., Cai, Y., \& O'Shea, K. E. (2018). Kinetic and Mechanistic Evaluation of Inorganic Arsenic Species Adsorption onto Humic Acid Grafted Magnetite Nanoparticles. Journal of Physical Chemistry C, 122(25), 13540-13547. doi:10.1021/acs.jpcc.7b12438

Singhal, P., Jha, S. K., Pandey, S. P., \& Neogy, S. (2017). Rapid extraction of uranium from sea water using $\mathrm{Fe} 3 \mathrm{O} 4$ and humic acid coated Fe304 nanoparticles. Journal of Hazardous Materials, 335, 152161. doi:10.1016/j.jhazmat.2017.04.043

Singhal, P., Pulhani, V., Ali, S. M., \& Ningthoujam, R. S. (2019). Sorption of different metal ions on magnetic nanoparticles and their effect on nanoparticles settlement. Environmental Nanotechnology, Monitoring \& Management, 11, 100202. doi:https://doi.org/10.1016/j. enmm.2018.100202

Singhal, P., Vats, B. G., \& Pulhani, V. (2020a). Magnetic nanoparticles for the recovery of uranium from sea water: Challenges involved from research to development. Journal of Industrial and Engineering Chemistry, 90, 17-35. doi:https://doi.org/10.1016/j. jiec.2020.07.035
Singhal, P., Vats, B. G., Yadav, A., \& Pulhani, V. (2020b). Efficient extraction of uranium from environmental samples using phosphoramide functionalized magnetic nanoparticles: Understanding adsorption and binding mechanisms. Journal of Hazardous Materials, 384, 121353. doi:https://doi.org/10.1016/j.jhazmat.2019.121353

Tang, Z., Zhao, X. L., Zhao, T. H., Wang, H., Wang, P. F., Wu, F. C., \& Giesy, J. P. (2016). Magnetic Nanoparticles Interaction with Humic Acid: In the Presence of Surfactants. Environmental Science \& Technology, 50(16), 8640-8648. doi:10.1021/acs.est.6b01749

Yang, S. T., Zong, P. F., Ren, X. M., Wang, Q., \& Wang, X. K. (2012). Rapid and Highly Efficient Preconcentration of Eu(III) by Core-Shell Structured Fe304@Humic Acid Magnetic Nanoparticles. Acs Applied Materials \& Interfaces, 4(12), 6890-6899. doi:10.1021/am3020372

Yang, T., \& Hodson, M. E. (2018). The copper complexation ability of a synthetic humic-like acid formed by an abiotic humification process and the effect of experimental factors on its copper complexation ability. Environmental Science and Pollution Research, 25(16), 15873-15884. doi:10.1007/s11356-018-1836-2

Zhang, Y. C., Yue, D. B., Lu, X. F., Zhao, K. Y., \& Ma, H. (2017). Role of ferric oxide in abiotic humification enhancement of organic matter. Journal of Material Cycles and Waste Management, 19(1), 585591. doi:10.1007/s10163-015-0435-2

Zhang, Y. C., Yue, D. B., \& Ma, H. (2015). Darkening mechanism and kinetics of humification process in catechol-Maillard system. Chemosphere, 130, 40-45.

Zhang, Y. C., Yue, D. B., Wang, X., \& Song, W. F. (2019). Mechanism of oxidation and catalysis of organic matter abiotic humification in the presence of $\mathrm{MnO} 2$. Journal of Environmental Sciences-China, 77, 167-173. doi:10.1016/j.jes.2018.07.002

Zou, J., Huang, J., Yue, D., \& Zhang, H. (2020). Roles of oxygen and Mn (IV) oxide in abiotic formation of humic substances by oxidative polymerization of polyphenol and amino acid. Chemical Engineering Journal, 393, 124734. doi:https://doi.org/10.1016/j. cej.2020.124734 